$$
\begin{array}{r}
\text { UM OLH } \\
\text { SOBRE A PRODU } \\
\text { DO BEIJU NA SEM } \\
\text { SANTA EM }
\end{array}
$$




\section{UM OLHAR SOBRE A PRODUÇÃO DO BEIJU NA SEMANA SANTA EM ARAÍ}


Este ensaio registra, cenas e fatos de uma prática cultural que ocorre no meio rural do nordeste paraense, especificamente na comunidade de Araí no município de Augusto Correa, quando na Semana Santa os católicos desse lugar se juntam para produzir beijus que depois de prontos são trocados e consumidos durante a festa da Páscoa.

O beiju é uma espécie de bolo que além de alimentar; se constituí em importante operador da religiosidade, de sociabilidade e reciprocidade entre aquele povo. Todo o processo de produção tem duração média de cinco dias. Começa com a coleta da mandioca que em seguida é colocada de molho em um riacho ${ }^{1}$ por três ou quatro dias, após esse tempo a mandioca amolece e é retirada da casca e transportada para a casa do forno, local onde a mandioca é macerada e misturada aos ingredientes e transformada em beijus.

\section{NOTAS}

${ }^{1}$ Pução e o nome que os nativos dão para o riacho onde colocam a mandioca de molho.

Miguel de Nazaré Brito Picanço micanbri2013@gmail.com 


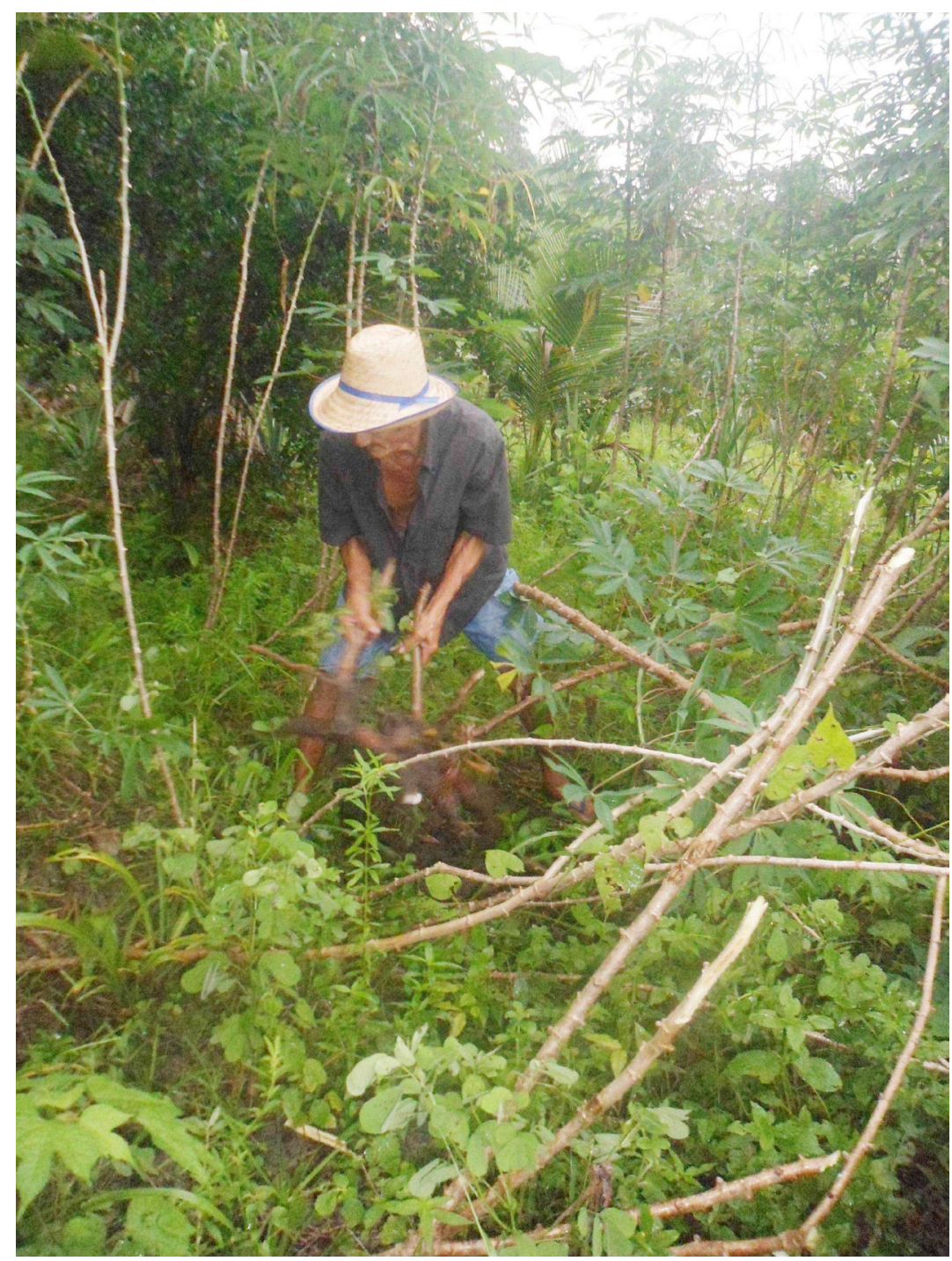

Figura 1 - Miguel de Nazaré Brito Picanço-2014. A coleta da mandioca. 
Picanço, M. de N. B.

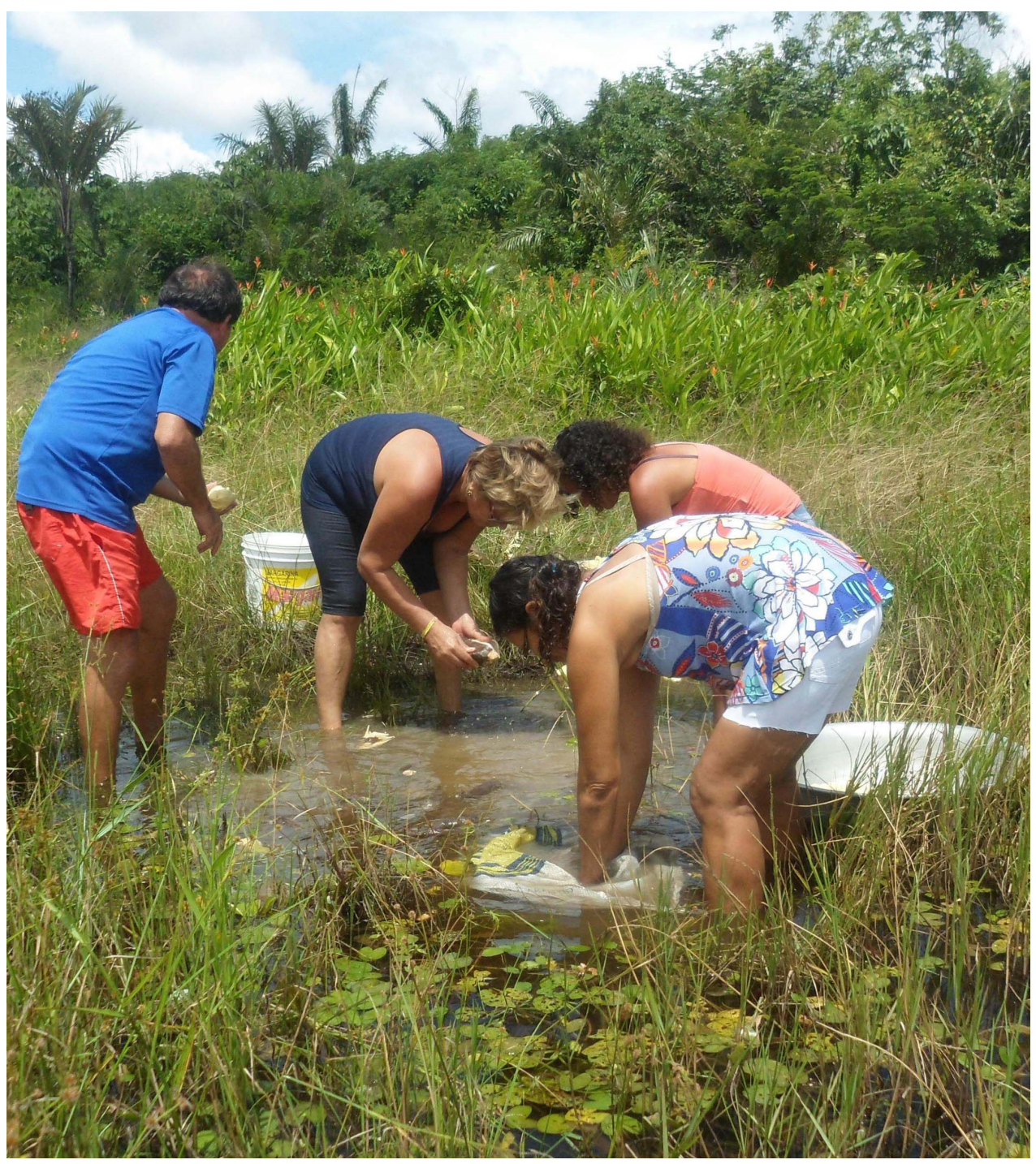

Figura 2 - Miguel de Nazaré Brito Picanço-2014. A mandioca no pução. 


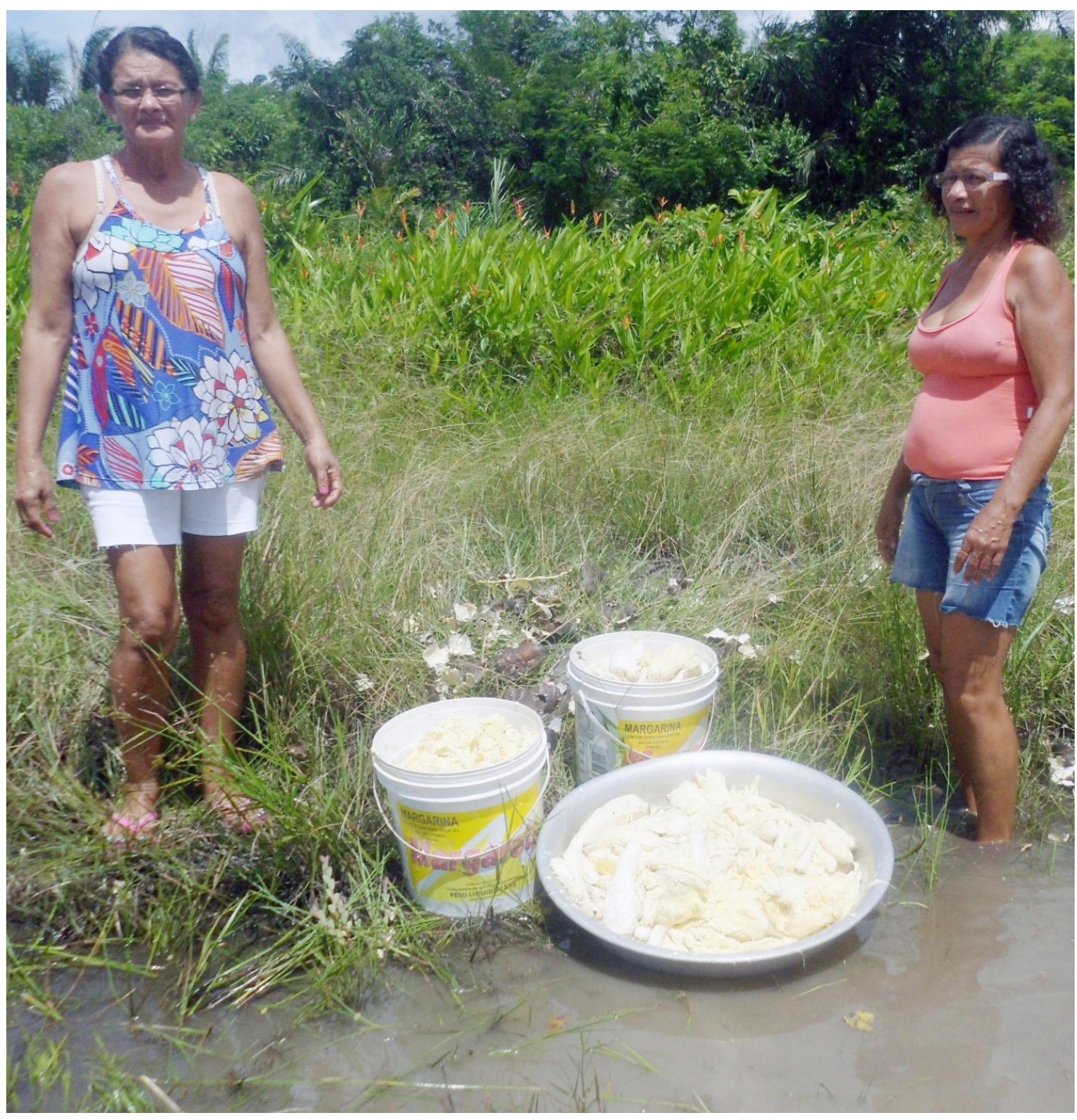

Figura 3 - Miguel de Nazaré Brito Picanço-2014. A mandioca é descascada. 


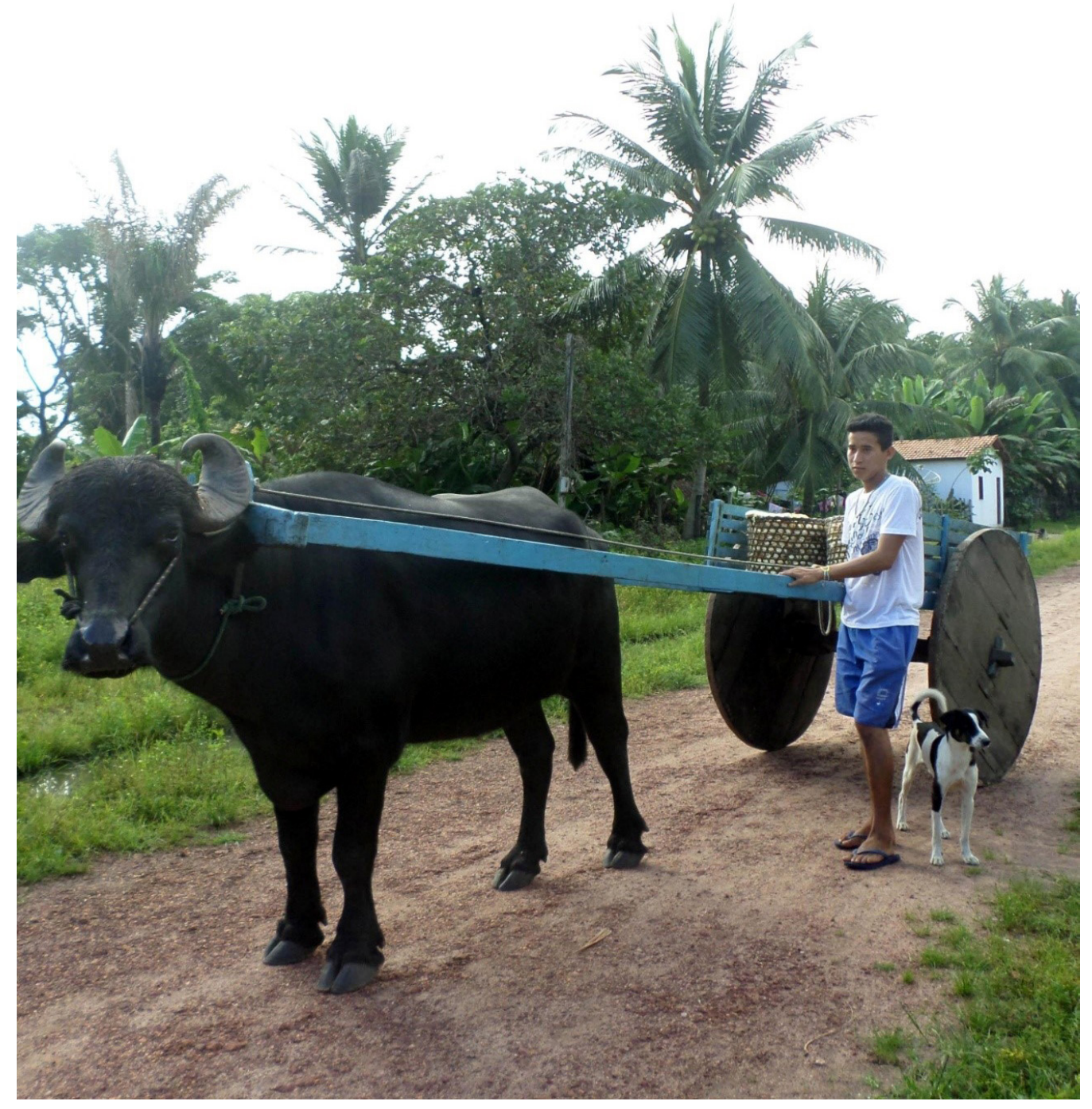

Figura 4 - Miguel de Nazaré Brito Picanço-2014. O transporte da mandioca. 


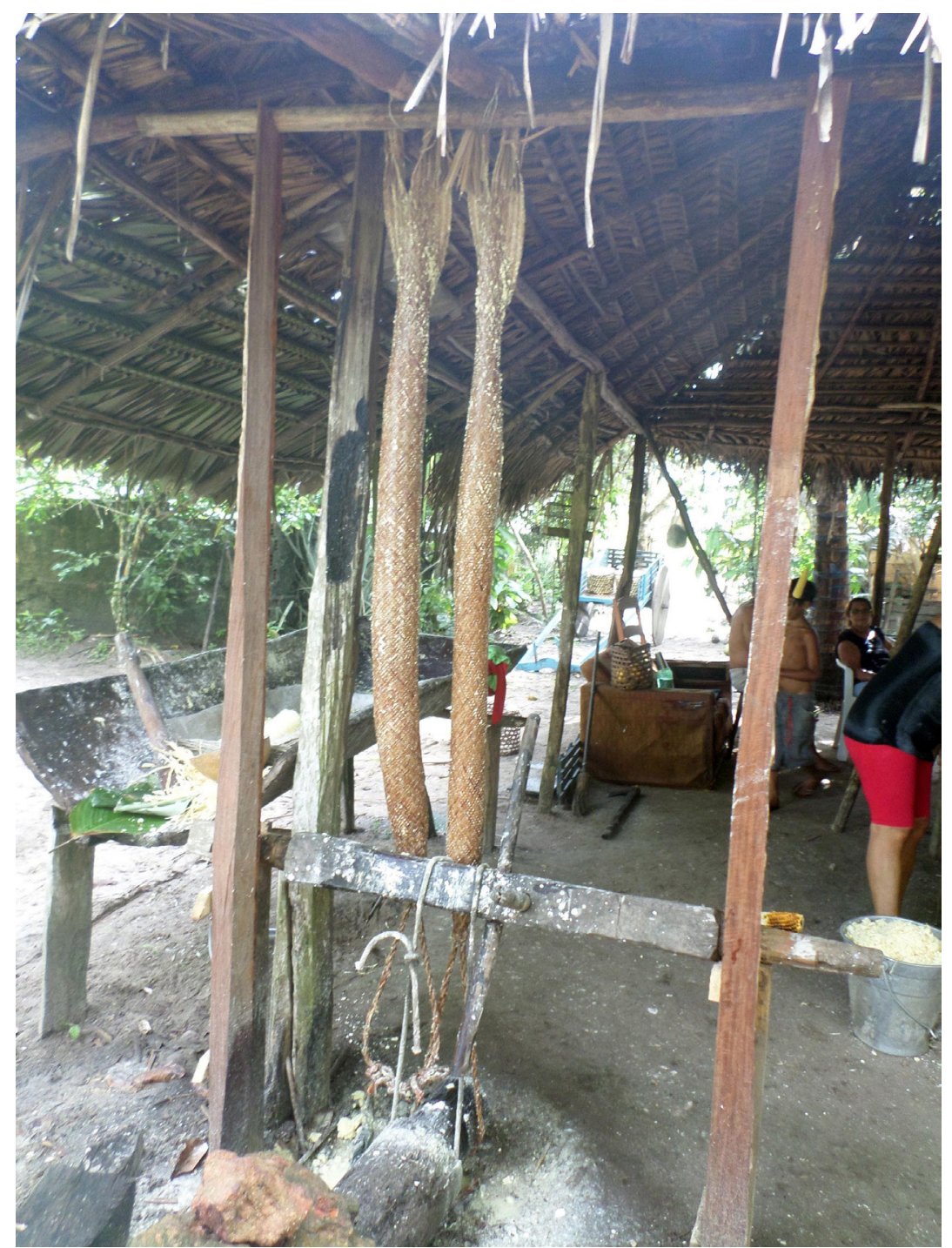

Figura 5 - Miguel de Nazaré Brito Picanço-2014. A mandioca é prensada. 
Picanço, M. de N. B.

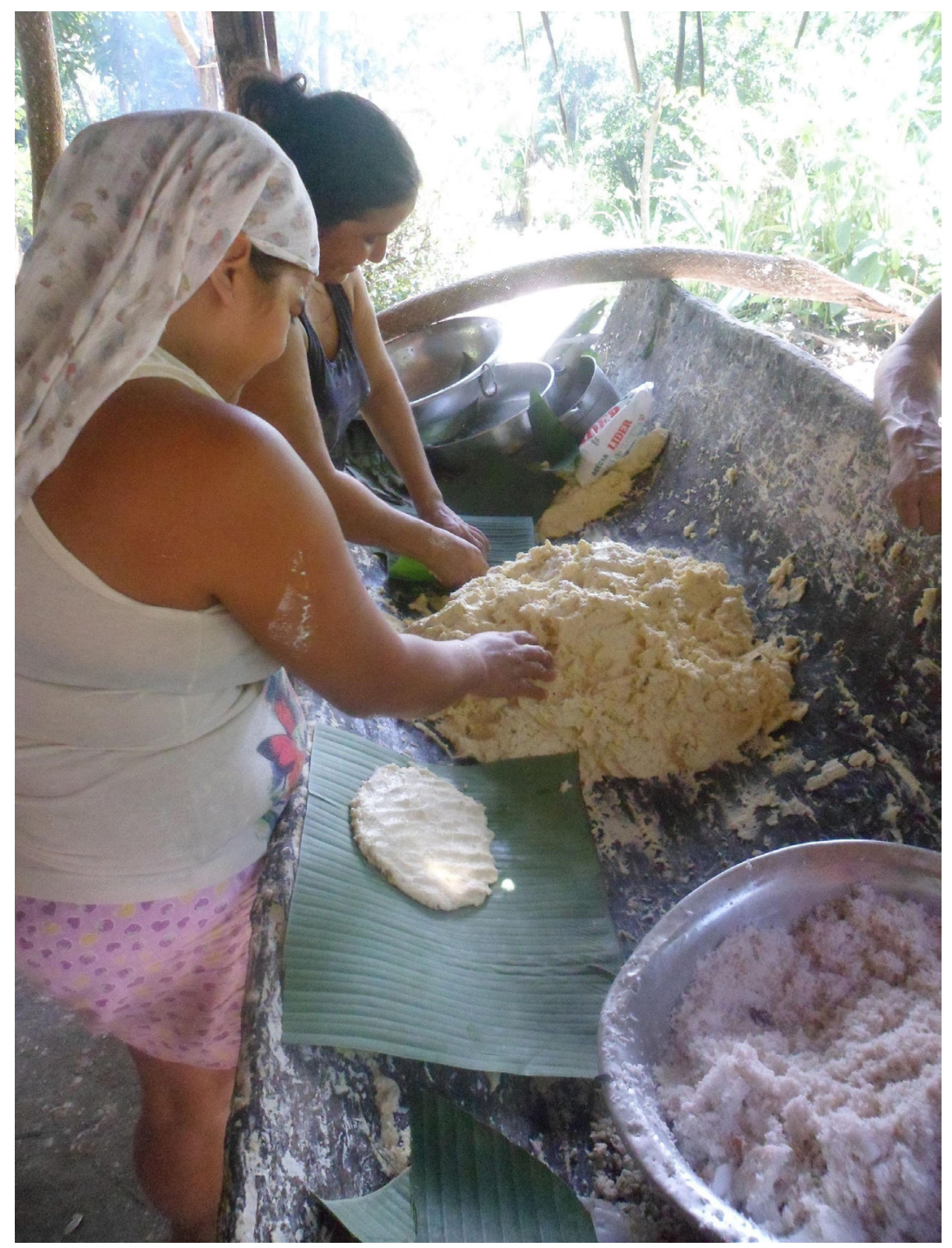

Figura 6 - Miguel de Nazaré Brito Picanço-2014. E a massa vara beiju. 


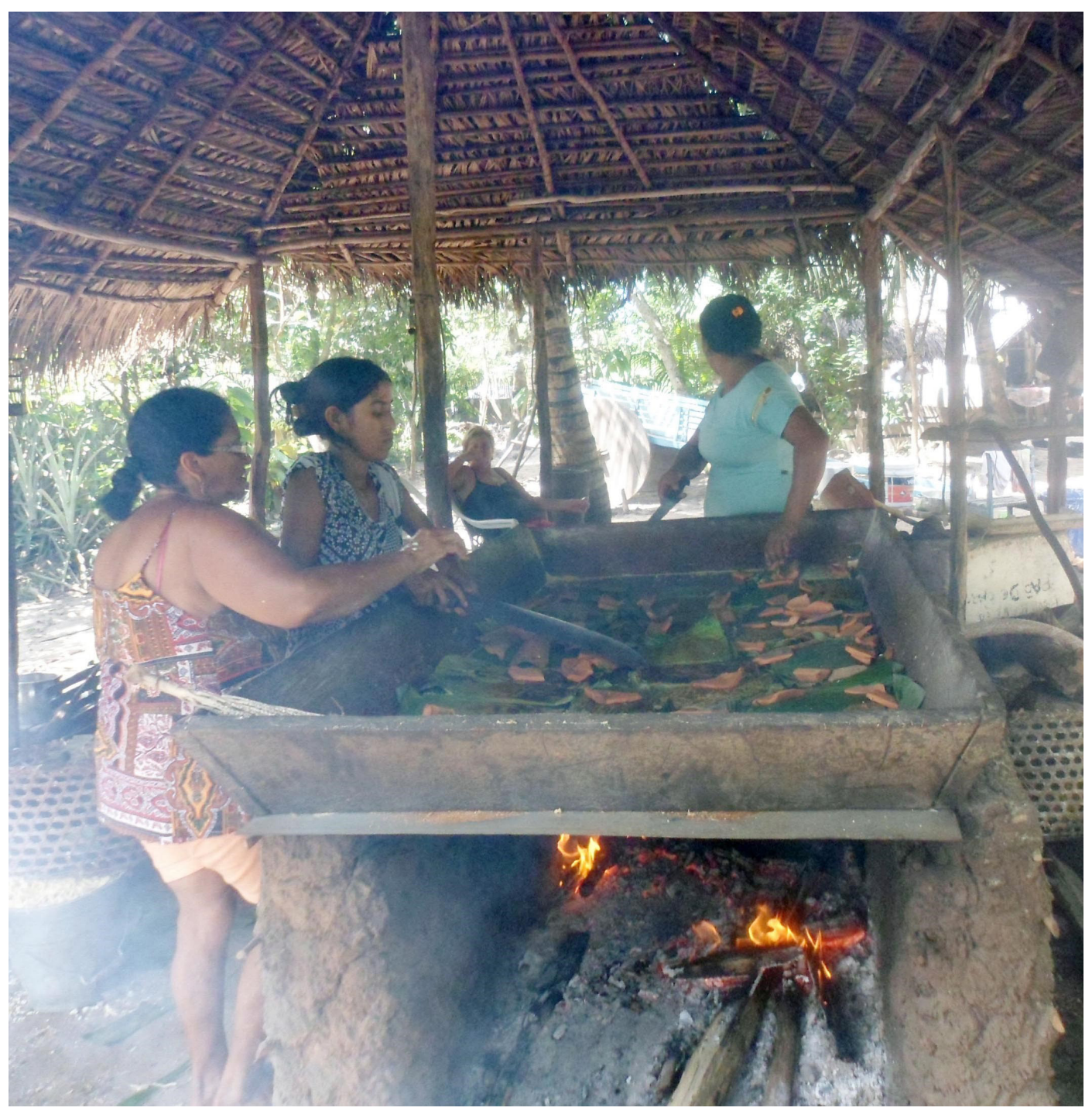

Figura 7 - Miguel de Nazaré Brito Picanço-2014. E o beiju é assado. 


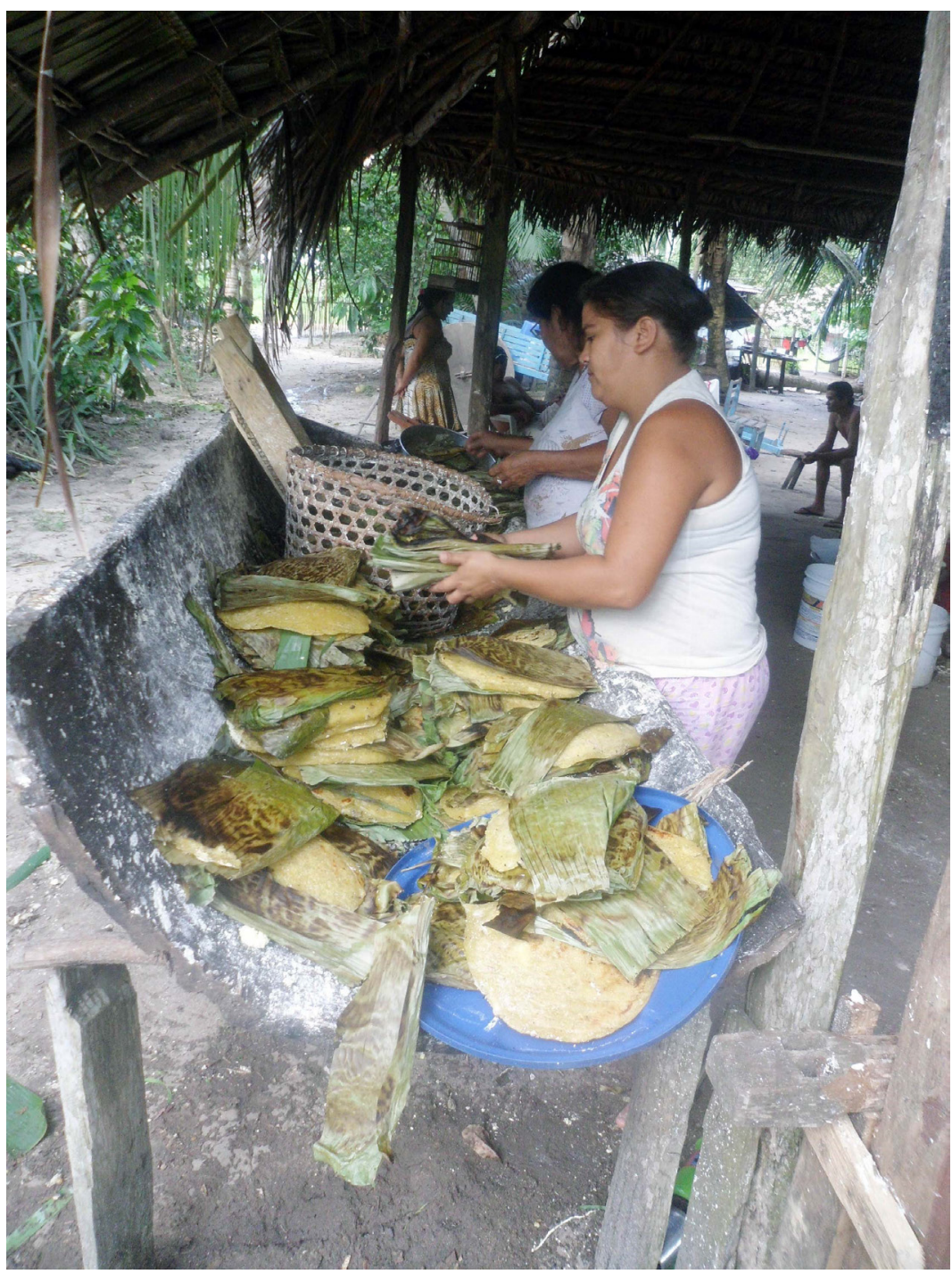

Figura 8 - Miguel de Nazaré Brito Picanço-2014. O beiju é repartido. 